\title{
Rescue Therapy of Delayed Gastric Perforation Caused by an External Drainage Using an Over-the-Scope Clip
}

\author{
Andrada Seicean $^{1,2}$, Carmen Cruciat ${ }^{1}$, Radu Motocu $^{3}$, Cristina Pojoga ${ }^{1}$, Marcel Gheorghiu $^{2}$, Radu Seicean $^{2,3}$
}

1) Regional Institute of

Gastroenterology and

Hepatology, Cluj-Napoca

2) Iuliu Hatieganu University

of Medicine and Pharmacy,

Cluj-Napoca

3) First Surgical Clinic,

Cluj-Napoca, Romania
Address for correspondence: Andrada Seicean

Regional Institute of

Gastroenterology and

Hepatology

19-21 Croitorilor Street,

Cluj-Napoca, Romania

andradaseicean@gmail.com
Received: 03.02.2019

Accepted: 18.04.2018

\begin{abstract}
This case reports a iatrogenic gastric fistula due to external draining successfully closed by using an overthe-scope clip. A 50-year old patient with a history of acute pancreatitis, segmental portal hypertension and splenectomy for splenic rupture, with long-term external drainage for a low volume pancreatic fistula, was referred to our hospital. The patient noticed the occurrence of a sudden increase of the drain flow and the immediate drainage of ingested liquid, with no fever or pain. An upper gastrointestinal endoscopy evidenced the gastric fistula with the presence of the drain inside the stomach near a gastric varix. The surgical approach was inappropriate due to bleeding risk. An over-the-scop clip was placed succeeding to stop the gastric flow. The external fistula closed one week later.
\end{abstract}

Key words: delayed perforation - gastro-cutaneous fistula - over-the-scope clip - portal hypertension

Abbreviations: GI: gastrointestinal; OTSC: over-the- scope clip.

\section{INTRODUCTION}

Gastrointestinal (GI) perforations, leakages and fistulas are full-thickness mural defects that can result in significant morbidity and mortality. The European Society of Gastrointestinal Endoscopy guidelines recommend that every identified perforation should be described as size and location, the possible endoscopic treatment used and whether air or carbon dioxide was used for insufflation [1]. For perforations below $1 \mathrm{~cm}$ in diameter, clips are useful, but for those over $1 \mathrm{~cm}$ in diameter, the overthe-scope clips (OTSC) are recommended. These devices, which encircle, lift and close full thickness defects, are considered as a less invasive procedure than surgery with omental patching. When required, the diversion of luminal content, and decompression of tension pneumoperitoneum or tension pneumothorax should also be performed [1]. In the case of no or failed endoscopic closure of the iatrogenic perforation, and in patients whose clinical condition is deteriorating, hospitalization and surgical advice are recommended, prior to OTSC placement [1].

\section{CASE REPORT}

We report the case of a 50-year old male patient, with a history of moderate biliary acute pancreatitis with operated walled-off pancreatic necrosis, who developed segmental portal hypertension and important collateral circulation (Fig. 1). One year later, he developed a spontaneous splenic rupture with hemoperitoneum. Splenectomy and distal pancreatectomy were performed and an external drainage was placed (Fig. 2). The patient refused the drain removal for six months because it drained 5-10 $\mathrm{ml}$ per day. Two days before readmission, he noticed that any ingested liquid was rapidly drained externally, without any pain or fever, and the quantity of liquid drained had increased considerably. The upper gastrointestinal endoscopy was performed under carbon dioxide insufflations and the plastic tube was seen protruding on the posterior wall of the stomach, near a gastric varix (Fig. 3). The patient was considered unsuitable for surgery due to the collateral circulation developed after the previous episode of acute pancreatitis [2]. The tube was slowly removed from the stomach, the perforation of 1 $\mathrm{cm}$ in diameter was visualized. The OTSC (Ovesco, Tübingen, Germany) was used for targeting the gastric perforation and 
each edge of the lesion was grasped with one of the two jaw parts of the OTSC twin grasper. The perforation rim was retracted into the OTSC, the tissue was aspirated and completely pulled into the cap, followed by the clip releasing and closure of the gastric defect and removal of the twin grasper from the tissue (Fig. 4). No contrast extravasation from the stomach was noted and the external flow stopped immediately. The whole procedure lasted 15 minutes. Standard cefalosporin was given for 3 days after the procedure.

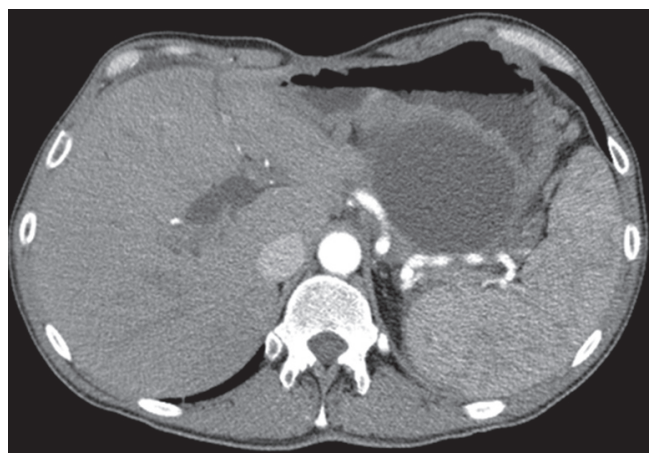

Fig. 1. Computer tomography scan of a pancreatic fluid collection after acute pancreatitis with important collateral circulation and splenomegaly.

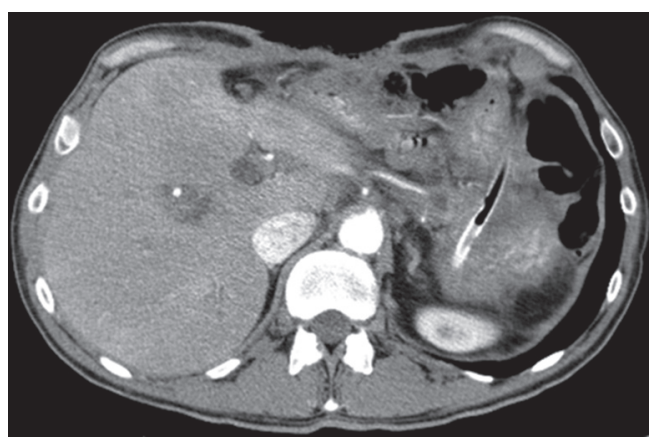

Fig. 2. Computer tomography scan after splenectomy and distal pancreatectomy; the plastic drain can be noticed.

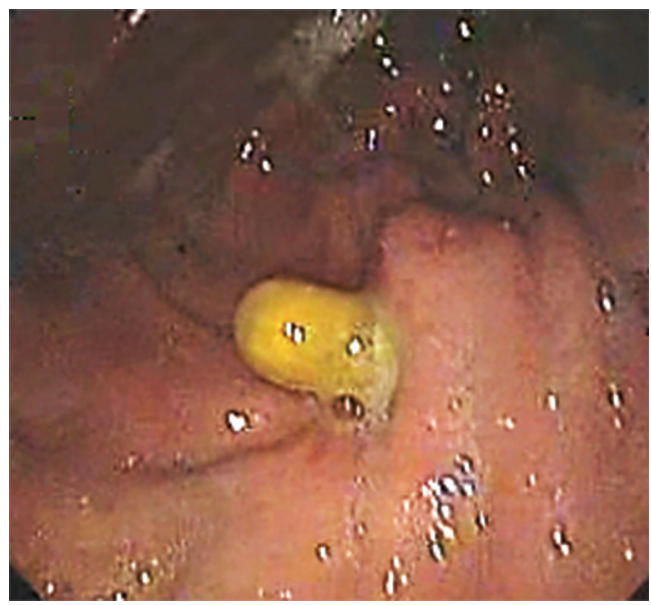

Fig. 3. Endoscopic view of the stomach with the plastic tube protruding on the posterior wall of the stomach. A gastric varix can be noticed nearby.

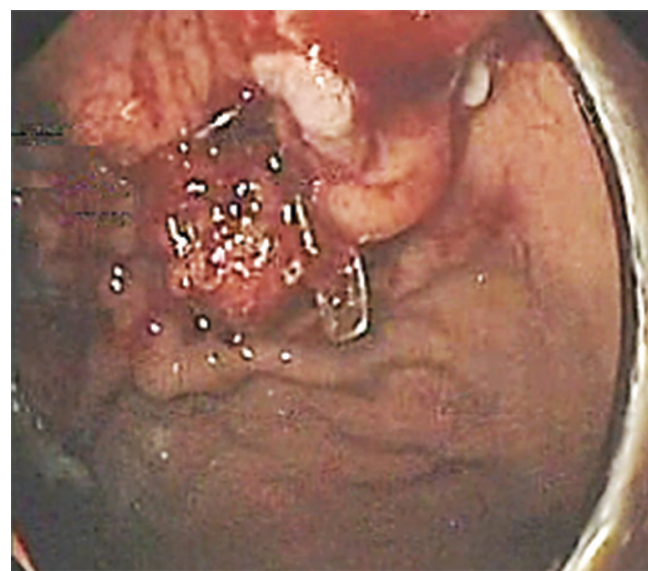

Fig. 4. Endoscopic view of the stomach with the "bear- claw" aspect of the OTSC clip released in the stomach wall which closed the gastric defect.

The tube was removed and the external fistula closed one week later. The outcome was uneventful three years later.

\section{DISCUSSION}

Delayed decubitus perforation of the GI tract due to external drainage is very rare. Similar cases have been reported for dialysis peritoneal catheters and it seems that the cessation of flow into the tube for more than one month is associated with a risk of adhesion to the GI wall with bowel perforations, usually treated surgically [3]. This report describes a successful closure of a perforation in the gastric wall, by using an OTSC in the difficult condition of segmental portal hypertension with gastric varices; the surgical approach was inappropriate due to a major bleeding risk.

This system is an endoscopic clipping device that provides a strong tissue grasp and compression without causing ischemia or laceration. Its design as a "bear claw" is useful when the tissue surrounding the defect is endured or inflamed. It has been used in the closure of larger GI acute perforations, leaks, fistulas, GI bleeding, full-thickness resection of tumors, and stent or feeding tube anchoring [4]. The clip is easy to use and mucosal incision can be used for optimizing the fistula closure.

There are two types of OTSC on the market: the Ovesco system (Ovesco Endoscopy AG, Tübingen, Germany) and the Padlock Clip (Aponos Medical, Kingston, NH, USA). The difference between the two systems consists of the placement of the position cable outside the endoscope for the Padlock system and inside the working channel for the Ovesco system. Additionally, the Ovesco system presents a twin grasper for easy approximation of gaping edges of a lesion before release of the OTSC clip, which we used in our case, or a three hook anchor for better approximation of tissue especially when everted or indurated. There are several types of Ovesco clips: the type with a long and large prong indicated for stomach closure, a traumatic type for organs with thin walls, such as the small intestine and large intestine, and an atraumatic type for hemorrhagic lesions. There are three indications for the use of the OTSC system: acute leaks and perforations, chronic leaks, fistulas and GI bleeding. 
The technical success rate of OTSC varies between 70 to $92 \%$ [4-10]. A large lesion size (greater than $20 \mathrm{~mm}$ ) and a delayed diagnosis (more than 1 week) were the major contributing factors for the overall unsuccessful clinical cases [5]. The technical disadvantages are related to the need for the complete withdrawal of the endoscope to mount the device to the tip and the failure to OTSC placement is related to a nonsuitable anatomic structure, rigidity of the surrounding tissue and large defects [10].

The gastric perforation is defined as an unintentional, acute iatrogenic, full-thickness defect in the GI tract [8]. It can occur after percutaneous gastrostomy placement, submucosal dissection, peptic ulcer or as a complication of upper GI surgery, but rarely after delayed decubitus lesion related to a plastic drain. The placement of OTSC is quite easy in the body of the stomach, as it was in our case, where the lumen is wide, but the placement near cardia or pylorus should be done carefully due to the risk of post-placement luminal stenosis [10]. The timing of OTSC placement is important, because the results are better when the OTSC clips are used as primary therapy [6], as in our patient. The rescue therapy, after a previous closure failure, was associated with a lower successful rate (43\% vs $69 \%$ ) [6].

The perforation closure is easiest in the colon and duodenum, followed by the rectum and stomach and the most difficult sites are the esophagus and small bowel [10].

Usually, the closure of perforations and leaks with OTSC decreases the need for surgery. However, misplacement of the clip with unsuccessful closure of the large defect or accidentally closure of the surrounding structures, such as the ureter or jejunal loops, require surgery [11-13] The accidentally releasing of OTSC on the tongue of the patient or outlet obstruction rectal syndrome have been reported [10]. Therefore, it is compulsory to visualize the discharged OTSC prior to the withdrawal of the endoscope [10]. Other complications could be the capture of a grasping instrument within the teeth of the clip [14].

The success rate of OTSC placement is higher for perforations (85-90\%) and leaks (33-73.3\%) than for fistulas (29-52\%), as reported by large studies [7, 10, 15-23].

The chronic upper and lower fistulas, defined as an abnormal communication between two epithelialized surfaces [6], can be closed with a high success rate (89\%), but only $53 \%$ of them had delayed clinical success [24]. The lower fistula closure, including rectovaginal fistula and Crohn's disease fistulas were disappointing in terms of postoperative pain, clip migration and the need for reintervention [25].

The OTSC can be used for sealing fistulas after a gastric sleeve [26] or anastomotic leaks of the GI tract. Additional methods for their closure are metallic stents, hemoclips, glue injection or endo-sponge application. The OTSC success rate in anastomotic leaks closure is higher in upper than in lower GI cases ( $83 \%$ vs $75 \%)$ [27].

Other indications are non-variceal upper and lower bleeding with a successful rate of stopping the bleeding over $85 \%[10,16$, 23 ] and with a low rate of mortality of $1.7 \%$, including patients with a high bleeding risk on antithrombotic therapy or in the case of recurrent bleeding $[27,28]$. However, variceal bleeding was stopped only exceptionally with OTSC $[29,30]$.
In our case, the drainage stopped immediately after the perforation closure and the tube was removed subsequently, similar to other reports [13]. The technique is easy and the results are good if the fistula has no inflammatory rim and the position of the endoscope allows a good approach of the lesion, such in our case. The cut-off of $30 \mathrm{~mm}$ for the size of the defect was respected in our case, where the diameter of the perforation was about $1 \mathrm{~cm}$ in diameter. Based on the clinical presentation, we assumed that the perforation developed two days before presentation, so we decided to grasp the fistula rim before suction in order to avoid the misplacement of the OTSC. There was important collateral circulation related to portal hypertension developed after acute pancreatitis in our patient, associated with hemorrhagic risk for surgery and we considered that the OTSC system was the only possibility for this patient with careful placement of the clip for avoiding the gastric varix. Few literature reports presented these clips as rescue therapy in portal hypertension as in fibrotic esophageal variceal bleeding or post-banding bleeding ulcers $[29,30]$. The good outcome for our patient was facilitated by the early presentation.

The OTSC system is nitinol and MRI compatible, but it is previewed to be a durable implant. Although it was not the case in our patient, the removal of the clip is suitable when the GI tract is obstructed by the clip or when there is a remaining adenomatous polyp which should be removed. For this purpose, there is a special cutting device for OTSC, which can be used preferably after 3 months. The attempt to remove the clip over this period of time might be difficult because the clip may grow deep into the gastrointestinal wall.

\section{CONCLUSION}

Delayed gastric perforation represents a rare, but severe complication of long-term external drainage. Its closure by using the OTSC is rapid, easy and safe.

\section{Conflicts of interest: None to declare.}

Authors' contribution: All the authors were involved in the management of patient. A.S., C.C., C.P., R.M. collected and analyzed the data. A.S. and M.G. drafted the manuscript. A.S. critically revised the manuscript. All authors approved the final version.

\section{REFERENCES}

1. Paspatis GA, Dumonceau JM, Barthet $M$, et al. Diagnosis and management of iatrogenic endoscopic perforations: European Society of Gastrointestinal Endoscopy (ESGE) Position Statement. Endoscopy 2014;46:693-711. doi:10.1055/s-0034-1377531

2. Abbott TEF, Ahmad T, Phull MK, et al; International Surcal Outcomes Study (ISOS) group. The surgical safety checklist and patient outcomes after surgery: a prospective observational cohort study, systematic review and meta-analysis. Br J Anaesth 2018;120:146-155. doi:10.1016/j. bja.2017.08.002

3. Wang R, Chen Z, Wang J, Zhang X, Shou Z, Chen J. Delayed bowel perforation in a peritoneal dialysis patient: a case report and literature review. Perit Dial Int 2014;34:460-466. doi:10.3747/ pdi.2012.00345 
4. Mönkemüller K, Peter S, Toshniwal J, et al. Multipurpose use of the 'bear claw' (over-the-scope-clip system) to treat endoluminal gastrointestinal disorders. Dig Endosc 2014;26:350-357. doi: 10.1111/den.12145

5. Sulz MC, Bertolini R, Frei R, Semadeni GM, Borovicka J, Meyenberger C. Multipurpose use of the over-the-scope-clip system ("Bear claw") in the gastrointestinal tract: Swiss experience in a tertiary center. World J Gastroenterol 2014;20:16287-16292. doi:10.3748/wjg.v20. i 43.16287

6. Haito-Chavez Y, Law JK, Kratt T, et al. International multicenter experience with an over-the-scope clipping device for endoscopic management of GI defects (with video). Gastrointest Endosc 2014;80:610-622. doi:10.1016/j.gie.2014.03.049

7. Voermans RP, Le Moine O, von Renteln D, et al. Efficacy of endoscopic closure of acute perforations of the gastrointestinal tract. Clin Gastroenterol Hepatol 2012;10:603-608. doi:10.1016/j. cgh.2012.02.005

8. Mercky P, Gonzalez JM, Aimore Bonin E, et al. Usefulness of overthe-scope clipping system for closing digestive fistulas. Dig Endosc 2015;27:18-24. doi:10.1111/den.12295

9. Parodi A, Repici A, Pedroni A, Blanchi S, Conio M. Endoscopic management of GI perforations with a new over-the-scope clip device (with videos). Gastrointest Endosc 2010;72:881-886. doi:10.1016/j. gie.2010.04.006

10. Honegger C, Valli PV, Wiegand N, Bauerfeind P, Gubler C. Establishment of Over-The-Scope-Clips (OTSC ${ }^{\varpi}$ ) in daily endoscopic routine. United European Gastroenterol J 2017;5:247-254. doi:10.1177/2050640616657273

11. Khater S, Rahmi G, Perrod G, et al. Over-the-scope clip (OTSC) reduces surgery rate in the management of iatrogenic gastrointestinal perforations. Endosc Int Open 2017;5:E389-E394. doi:10.1055/s-0043-104862

12. Tashima T, Ohata K, Sakai E, et al. Efficacy of an over-the-scope clip for preventing adverse events after duodenal endoscopic submucosal dissection: a prospective interventional study. Endoscopy 2018;50:487496. doi:10.1055/s-0044-102255

13. Baron TH, Song LM, Ross A, Tokar JL, Irani S, Kozarek RA. Use of an over-the-scope clipping device: multicenter retrospective results of the first U.S. experience (with videos). Gastrointest Endosc 2012;76:202208. doi:10.1016/j.gie.2012.03.250

14. Wedi E, Gonzalez S, Menke D, Kruse E, Matthes K, Hochberger J. One hundred and one over-the-scope-clip applications for severe gastrointestinal bleeding, leaks and fistulas. World J Gastroenterol 2016;22:1844-1853. doi:10.3748/wjg.v22.i5.1844

15. Shoar S, Poliakin L, Khorgami Z, et al. Efficacy and Safety of the Over-the-Scope Clip (OTSC) System in the Management of Leak and Fistula After Laparoscopic Sleeve Gastrectomy: a Systematic Review. Obes Surg 2017;27:2410-2418. doi:10.1007/s11695-017-2651-4

16. Kobara H, Mori H, Nishiyama N, et al. Over-the-scope clip system: A review of 1517 cases over 9 years. J Gastroenterol Hepatol 2019;34:22 30. doi:10.1111/jgh.14402
17. Mangiavillano B, Morandi E, Arena M, Santoro T, Masci E. An 'omental patch' created during over-the-scope clipping completely sealed a duodenal perforation after endoultrasonography. Therap Adv Gastroenterol 2014;7:280-281. doi:10.1177/1756283X14540223

18. Robotis J, Karabinis A. Esophageal Perforation due to Transesophageal Echocardiogram: New Endoscopic Clip Treatment. Case Rep Gastroenterol 2014;8:235-239. doi:10.1159/000365321

19. Pérez-Cuadrado-Robles E, Flores-Pastor B, Bebia P, Pérez-CuadradoMartínez E, Aguayo-Albasini JL. Endoscopic management of a perforation during diagnostic colonoscopy using $\mathrm{OVESCO}^{\infty}$ clip. Cir Esp (English Edition) 2016;94:e25-e27. doi:10.1016/j.ciresp.2014.03.004

20. Donatelli G, Dumont JL, Vergeau BM, et al. Colic and gastric over-thescope clip (Ovesco) for the treatment of a large duodenal perforation during endoscopic retrograde cholangiopancreatography. Therap Adv Gastroenterol 2014;7:282-284. doi:10.1177/1756283X14551672

21. Díez-Redondo P, Blanco JI, Lorenzo-Pelayo S, et al. A novel system for endoscopic closure of iatrogenic colon perforations using the Ovesco ${ }^{\circ}$ clip and omental patch. Rev Esp Enferm Dig 2012;104:550-552.

22. Yilmaz B, Unlu O, Roach EC, et al. Endoscopic clips for the closure of acute iatrogenic perforations: Where do we stand? Dig Endosc 2015;27:641-648. doi:10.1111/den.12482

23. Kirschniak A, Subotova N, Zieker D, Königsrainer A, Kratt T. The OverThe-Scope Clip (OTSC) for the treatment of gastrointestinal bleeding, perforations, and fistulas. Surg Endosc 2011;25:2901-2905. doi:10.1007/ s00464-011-1640-2

24. Law R, Wong Kee Song LM, Irani S, Baron TH. Immediate technical and delayed clinical outcome of fistula closure using an over-the-scope clip device. Surg Endosc 2015;29:1781-1786. doi:10.1007/s00464-014-3860-8

25. Gautier M, Godeberge P, Ganansia R, et al. Easy clip to treat anal fistula tracts: a word of caution. Int J Colorectal Dis 2015;30:621-624. doi:10.1007/s00384-015-2146-5

26. Keren D, Eyal O, Sroka G, et al. Over-the-Scope Clip (OTSC) System for Sleeve Gastrectomy Leaks. Obes Surg 2015;25:1358-1363. doi:10.1007/ s11695-014-1540-3

27. Schmidt A, Gölder S, Goetz M, et al. Over-the-Scope Clips Are More Effective Than Standard Endoscopic Therapy for Patients With Recurrent Bleeding of Peptic Ulcers. Gastroenterology 2018;155:674686.e6. doi:10.1053/j.gastro.2018.05.037

28. Manno M, Mangiafico S, Caruso A, et al. First-line endoscopic treatment with OTSC in patients with high-risk non-variceal upper gastrointestinal bleeding: preliminary experience in 40 cases. Surg Endosc 2016;30:2026-2029. doi:10.1007/s00464-015-4436-y

29. Robles-Medranda C, Puga-Tejada M, Ospina J, Valero M, Lukashok HP. Over-the-scope clip in the management of fibrotic esophageal variceal bleeding (with video). Gastrointest Endosc 2017;86:732-733. doi:10.1016/j.gie.2017.04.027

30. Cahyadi O, Caca K, Schmidt A. Over-the-scope clip is an effective therapy for postbanding ulcer bleeding after initially successful transjugular intrahepatic portosystemic shunt therapy. Endoscopy 2017;49:E258-E259. doi:10.1055/s-0043-115890 